\title{
INPUT/OUTPUT IN \\ PARALLEL AND DISTRIBUTED \\ COMPUTER SYSTEMS
}


THE KLUWER INTERNATIONAL SERIES IN ENGINEERING AND COMPUTER SCIENCE 


\title{
INPUT/OUTPUT IN \\ PARALLEL AND DISTRIBUTED \\ COMPUTER SYSTEMS
}

edited by

\author{
Ravi Jain \\ Bell Communications Research \\ Morristown,New Jersey, USA \\ John Werth \\ University of Texas at Austin \\ Austin, Texas, USA \\ James C. Browne \\ University of Teas at Austin \\ Austin, Texas, USA
}

KLUWER ACADEMIC PUBLISHERS

Boston / Dordrecht / London 


\section{Distributors for North America:}

Kluwer Academic Publishers

101 Philip Drive

Assinippi Park

Norwell, Massachusetts 02061 USA

Distributors for all other countries:

Kluwer Academic Publishers Group

Distribution Centre

Post Office Box 322

3300 AH Dordrecht, THE NETHERLANDS

\section{Library of Congress Cataloging-in-Publication Data}

A C.I.P. Catalogue record for this book is available from the Library of Congress.

ISBN-13: 978-1-4612-8607-3

e-ISBN-13: 978-1-4613-1401-1

DOI: $10.1007 / 978-1-4613-1401-1$

Copyright (C) 1996 by Kluwer Academic Publishers

Softcover reprint of the hardcover 1st edition 1996

All rights reserved. No part of this publication may be reproduced, stored in a retrieval system or transmitted in any form or by any means, mechanical, photocopying, recording, or otherwise, without the prior written permission of the publisher, Kluwer Academic Publishers, 101 Philip Drive, Assinippi Park, Norwell, Massachusetts 02061

Printed on acid-free paper. 
To

Meera, Laurie and Gayle 


\section{CONTENTS}

\section{Part I INTRODUCTION}

1 IOO IN PARALLEL AND DISTRIBUTED SYSTEMS: AN INTRODUCTION

Ravi Jain, John Werth and J. C. Browne

1 Introduction

2 Survey of $\mathrm{I} / \mathrm{O}$ issues

3 Trends and emerging concerns 15

4 Summary 20

2 AN INTRODUCTION TO PARALLEL I/O MODELS AND ALGORITHMS

Elizabeth Shriver and Mark Nodine

1 Introduction

2 The Parallel Disk Model 34

3 Parallel Disk Model algorithms $\quad 42$

4 Other two-level parallel-I/O memory models and their algorithms 56

5 Related systems approaches $\quad 58$

6 Conclusions $\quad 60$

3 ISSUES IN COMPILING I/O INTENSIVE PROBLEMS

Rajesh Bordawekar and Alok Choudhary 69

1 Introduction $\quad 69$

2 Architectural Model $\quad 70$ 
3 Programming Model $\quad 73$

4 Working spaces in I/O Intensive Parallel Programs 75

5 Execution Models $\quad 79$

6 Compiling Out-of-core Parallel Programs 83

7 Summary $\quad 94$

4 INTRODUCTION TO MULTIPROCESSOR I/O ARCHITECTURE

David Kotz $\quad 97$

1 Introduction $\quad 97$

2 Review and Terminology 98

3 Example architectures $\quad 100$

4 Disk I/O 104

5 Tape I/O 116

6 Graphics I/O 117

7 Network I/O 117

8 Summary 118

$\begin{array}{ll}\text { Part II SYSTEM SOFTWARE } & 125\end{array}$

5 OVERVIEW OF THE MPI-IO PARALLEL I/O INTERFACE

Peter Corbett, Dror Feitelson, Sam Fineberg, Yarsun Hsu,

Bill Nitzberg, Jean-Pierre Prost, Marc Snir, Bernard Traversat, and Parkson Wong

1 Parallel I/O 128

2 Overview of MPI-IO 130

3 Data Partitioning in MPI-IO 131

4 MPI-IO Data Access Functions 134

5 Miscellaneous Features 140

6 Current Status 141

APPENDIX A Transposing a 2-D Matrix 141

REFERENCES 143 


\section{RUNTIME SUPPORT FOR OUT-OF-CORE} PARALLEL PROGRAMS

Rajeev Thakur and Alok Choudhary

1 Introduction

2 Motivating Example

3 Extended Two-Phase Method

4 Partitioning I/O Among Processors

5 Performance

6 Advantages

7 Conclusions

7 PARALLEL IO WORKLOAD CHARACTERISTICS USING VESTA

Sandra Johnson Baylor and C. Eric Wu

1 Introduction

2 Architecture and Parallel File System

3 Applications

4 Methodology

5 Results

6 Conclusion

8 VIDEO ON DEMAND USING THE VESTA PARALLEL FILE SYSTEM

Edgar T. Kalns and Yarsun Hsu

1 Introduction

2 Related Work

3 Vesta Parallel File System Overview

4 VoD Experimentation Environment

5 Vesta VoD Performance

6 Conclusion

9 LOW-LEVEL INTERFACES FOR HIGH-LEVEL PARALLEL I/O

Nils Nieuwejaar and David Kotz

1 Introduction

2 The Conventional Interface 
3 Access Patterns 207

4 File System Interfaces 211

5 Other Unconventional Interfaces $\quad 219$

6 Conclusion 221

10 SCALABLE CONCURRENCY CONTROL FOR PARALLEL FILE SYSTEMS

Steven A. Moyer and V. S. Sunderam 225

1 Introduction 225

2 Volatile Transactions 227

3 Implementation 228

4 Observations 231

5 Experimental Results 232

6 Related Work 238

7 Conclusions 239

APPENDIX A Deadlock Avoidance with Progress 240

11 IMPROVING THE PERFORMANCE OF

PARALLEL I/O USING DISTRIBUTED SCHEDULING ALGORITHMS

Dannie Durand, Ravi Jain and David Tseytlin 245

1 Introduction $\quad 246$

2 Background 246

3 Problem Description 248

4 A Distributed Scheduling Algorithm 251

5 Experimental Results 256

6 Extensions 263

7 Conclusions $\quad 264$

APPENDIX A A bound on the number of holes 268

12 PLACEMENT-RELATED PROBLEMS IN SHARED DISK I/O

J.B. Sinclair, J. Tang and P.J. Varman 271

1 Introduction $\quad 271$

2 External Merging 273

3 Analysis of a 2-Disk System 278 
4 Analysis of a Multi-Disk System 282

5 Solutions to Racing 285

6 Summary 288

$\begin{array}{lll}\text { Part III ARCHITECTURE } & 291\end{array}$

13 PERFORMANCE EVALUATION OF A MASSIVELY PARALLEL I/O SUBSYSTEM

Sandra Johnson Baylor, Caroline Benveniste, and Yarsun Hsu 293

1 Introduction $\quad 293$

2 The Vulcan Architecture 295

3 Simulation Methodology 299

4 Results 302

5 Conclusion 310

14 HETEROGENEOUS IO CONTENTION IN A SINGLE-BUS MULTIPROCESSOR

Steven H. VanderLeest and Ravishankar K. Iyer 313

1 Introduction 313

2 Related Work 314

3 Description of Experiment 315

4 Preliminary Analysis $\quad 320$

5 The Performance Impact of I/O Contention 323

6 Concluding Remarks 329

15 HCSA: A HYBRID CLIENT-SERVER ARCHITECTURE

Gerhard A. Schloss and Michael Vernick 333

1 Introduction 333

2 Architectures 334

3 Hybrid Client-Server Architecture 336

4 File Access Protocols 339

5 HCSA Performance Study 341

6 Conclusions 348

REFERENCES $\quad 349$ 


\section{A SCALABLE DISK SYSTEM WITH DATA}

\section{RECONSTRUCTION FUNCTIONS}

Haruo Yokota and Yasuyuki Mimatsu 353

1 Introduction 353

2 Applying Parity Technique on an Interconnection Network 356

3 Estimation of the Response Time and Throughput 360

4 An Experimental System and Performance Evaluation 364

5 Discussion on the Reliability 368

6 Concluding Remarks 370

17 AN EXPERIMENTAL MEMORY-BASED I/O SUBSYSTEM

Abhaya Asthana and Mark Cravatts and Paul Krzyzanowski 373

1 Introduction $\quad 373$

2 SWIM active memory $\quad 374$

3 System architecture $\quad 376$

4 An object based programming model 377

5 Built-in support mechanisms 379

6 Prototype status 382

7 Application examples 383

8 Conclusion 389 


\section{PREFACE}

I/O for parallel and distributed computer systems has drawn increasing attention over the last few years as it has become apparent that I/O performance, rather than CPU performance, may be the key limiting factor in the performance of future systems. This $I / O$ bottleneck is caused by the increasing speed mismatch between processing units and storage devices, the use of multiple processors operating simultaneously in parallel and distributed systems, and by the increasing $\mathrm{V} / \mathrm{O}$ demands of new classes of applications, like multimedia. It is also important to note that, to varying degrees, the I/O bottleneck exists at multiple levels of the memory hierarchy. All indications are that the $\mathrm{I} / \mathrm{O}$ bottleneck will be with us for some time to come, and is likely to increase in importance.

These realizations prompted us to advocate that the $\mathrm{I} / \mathrm{O}$ bottleneck be addressed systematically at all levels of parallel and distributed system design. Thus while there are solutions which focus on one aspect of the system (e.g., architectural solutions like RAID), we felt that the benefits of these solutions would not be realized unless I/O-efficient design was integrated into applications, algorithms, compilers, operating systems, and architectures for parallel and distributed systems. With this view we initiated, in 1993, a workshop dedicated to I/O in parallel and distributed systems, held in conjunction with the International Parallel Processing Symposium (IPPS). The workshop drew substantial interest, and has now become an annual event. Papers submitted to the workshop were refereed, and in 1994 and 1995 about 30\%-40\% of the submitted papers were accepted for presentation. In 1996 the workshop on I/O in Parallel and Distributed Systems (IOPADS) is being held as an independent workshop with the Federated Computing Research Conference, and continues to draw international research participation.

This book is divided into three parts. Part I, the Introduction, contains four invited chapters which provide a tutorial and survey of $\mathrm{I} / \mathrm{O}$ issues in parallel and distributed systems. The chapters in Parts II and III contain selected research papers from the 1994 and 1995 IOPADS workshops; many of these papers have been substantially revised and updated for inclusion in this volume. Part II collects the papers from both years which dealt with various aspects of system software, and Part III those addressing primarily architectural issues. 
The first chapter in Part I provides an overview of $\mathrm{V} / \mathrm{O}$ issues, and surveys upcoming trends in this area, such as the convergence of networking and $\mathrm{I} / \mathrm{O}$, the increasing importance of the Internet and World-Wide Web as a new level of the system memory hierarchy, and the challenges posed by mobile and wireless computing. Chapter 2 by Shriver and Nodine presents an introduction to parallel I/O models and algorithms. Chapter 3 by Thakur and Choudhary, and Chapter 4 by Kotz, provide introductions to compiler issues and architectural approaches, respectively. We hope Part I will prove a useful source for graduate students and researchers new to the area.

The papers in Part II include those on compiler support, programming models, interfaces, file systems and scheduling. Chapter 5, by a team from IBM and NASA, presents the MPI-IO parallel I/O interface, and Chapter 6 by Thakur and Choudhary describes work on runtime support for out-of-core data parallel algorithms. Chapter 7 by Baylor et al presents a summary of the Vesta parallel file system developed at IBM, and its use for collecting parallel I/O workload characteristics, while Chapter 8 by Kalns and Hsu describes its use for an interesting and important application, video-on-demand. In Chapter 9, Nieuwejaar and Kotz present the results of tracing a parallel file system for scientific applications; the results indicate extensions needed to the interface provided to the programmer. Moyer and Sunderam, in Chapter 10, address the concurrency control issues that can arise when even a single read or write operation results in parallel $\mathrm{I} / \mathrm{O}$ operations on multiple storage devices. In Chapter 11 , Durand et al present distributed algorithms for scheduling parallel $\mathrm{I} / \mathrm{O}$ operations so as to minimize their completion time. In Chapter 12, Sinclair et al describe scenarios in which multiple processes engaging in parallel $\mathrm{L} / \mathrm{O}$ can conflict such that a subset of them monopolize the $\mathrm{I} / \mathrm{O}$ resources; this work has implications for data allocation and task partitioning in parallel systems.

Part III of the book focuses on issues relating to system architecture. Chapter 13, by Baylor et al of IBM, describes a performance evaluation of the massively parallel I/O subsystem of the Vulcan MPP, with results on the placement of I/O nodes in the system. VanderLeest and Iyer present, in Chapter 14, a methodology for measuring bus contention, a critical resource in parallel $\mathrm{I} O \mathrm{O}$, and the results of such a study on a specific system. In Chapter 15, Schloss and Vernick present a Hybrid Client-Server Architecture, in which the traditional client-server architecture is modified to give clients access to both the server and its disks. In Chapter 16, Yokota and Mimatsu propose Data-reconstruction networks for I/O subsystems, where each node has a set of disks and nodes are interconnected by a network separate from the primary processor interconnection network. Finally, in Chapter 17, Asthana et al describe an $\mathrm{I} / \mathrm{O}$ subsystem in which processing logic is associated with each memory chip, offloading some low-level I/O-related tasks from the CPU and thus speeding up overall system operation. 


\section{Preface}

The depth and breadth of the chapters in Parts II and III indicates the vitality of this fastgrowing research area, and we hope they will stimulate further study and integration of approaches for alleviating the $\mathrm{I} / \mathrm{O}$ bottleneck.

We would like to thank the members of the IOPADS 1994 and 1995 program committees who reviewed papers. The program committee members were: Abhaya Asthana (AT\&T Bell Labs), Larry Berdahl (Lawrence Livermore), Peter Chen (Univ. of Michigan), Alok Choudhary (Syracuse), Peter Corbett (IBM Watson), Tom Cormen (Dartmouth), David DeWitt (Univ. of Wisconsin), Sam Fineberg (NASA Ames), Shahram Ghandeharizadeh (USC), Paul Messina (Caltech), John Nickolls (MasPar), and Wayne Roiger (Cray Research). We also thank the many other reviewers who provided us with reviews of the submitted papers. Papers from the 1994 Workshop also appeared, in condensed form, in the ACM SIGARCH newsletter "Computer Architecture News", Oct. 1994; thanks are due to Doug DeGroot, editor, for his help in that regard. We thank Scott Delman of Kluwer for his help and patience during the long process of preparing this book, and Ravi Jain would like to thank Michael Kramer of Bellcore for his support.

Finally, we would like to thank the organizers of IPPS, and especially IPPS Chair Viktor Prasanna, for the opportunity to hold the IOPADS workshops in order to bring together researchers addressing the $\mathrm{I} / \mathrm{O}$ issues in parallel and distributed systems.

Ravi Jain, John Werth and J. C. Browne 